\title{
Fate of Mammalian Cochlear Hair Cells and Stereocilia after Loss of the Stereocilia
}

\author{
Shuping Jia, ${ }^{1}$ Shiming Yang (杨仕明), ${ }^{2}$ Weiwei Guo (郭维 维), ${ }^{2}$ and David Z. Z. He ${ }^{1}$ \\ ${ }^{1}$ Department of Biomedical Sciences, Creighton University School of Medicine, Omaha, Nebraska 68178, and 2Department of Otolaryngology, \\ Head and Neck Surgery, Institute of Otolaryngology, 301 Hospital, Beijing 100853, People's Republic of China
}

Cochlear hair cells transduce mechanical stimuli into electrical activity. The site of hair cell transduction is the hair bundle, an array of stereocilia with different height arranged in a staircase. Tip links connect the apex of each stereocilium to the side of its taller neighbor. The hair bundle and tip links of hair cells are susceptible to acoustic trauma and ototoxic drugs. It has been shown that hair cells in lower vertebrates and in the mammalian vestibular system may survive bundle loss and undergo self-repair of the stereocilia. Our goals were to determine whether cochlear hair cells could survive the trauma and whether the tip link and/or the hair bundle could be regenerated. We simulated the acoustic trauma-induced tip link damage or stereociliary loss by disrupting tip links or ablating the hair bundles in the cultured organ of Corti from neonatal gerbils. Hair-cell fate and stereociliary morphology and function were examined using confocal and scanning electron microscopies and electrophysiology. Most bundleless hair cells survived and developed for $\sim 2$ weeks. However, no spontaneous hair-bundle regeneration was observed. When tip links were ruptured, repair of tip links and restoration of mechanotransduction were observed in $<24 \mathrm{~h}$. Our study suggests that the dynamic nature of the hair cell's transduction apparatus is retained despite the fact that regeneration of the hair bundle is lost in mammalian cochlear hair cells.

\section{Introduction}

Cochlear hair cells are neuroepithelial cells characterized by hair bundles on their apical surface (Fettiplace and Hackney, 2006). Hair cells transduce mechanical stimuli into electrical activity (Hudspeth and Corey, 1977). The site of hair cell transduction is the hair bundle, an array of modified microvilli or stereocilia arranged in a staircase. Adjacent stereocilia are connected along their shafts by side links, whereas tip links (Pickles et al., 1984) extend from the apex of each stereocilium to the side of its taller neighbor. Recent evidence suggests that cadherin 23 and protocadherin 15 interact to form tip-link filaments (Kazmierczak et al., 2007). Stereocilia have a core of actin filaments (Tilney and Tilney, 1986), which are cross-linked with espin and fimbrin (Bartles, 2000) and enshrouded by plasma membrane. Myosin 1c is believed to link the transduction channels to the actin core of the stereocilia to adjust the tension of the tip links and to mediate

Received July 6, 2009; revised 0ct. 21, 2009; accepted 0ct. 28, 2009.

This work was supported by National Institutes of Health (NIH) Grants R01 DC004696 and R21 DC009908 to D.Z.Z.H., and by Grants 30871398 and 30730040 to S.Y. and 30628030 to D.Z.Z.H. from the National Natural Science Foundation of China. This work was also supported by Grant G20RR024001 from the National Center for Research Resources (NCRR). The content is solely the responsibility of the authors and does not necessarily represent the official views of the National Center for Research Resources or the NIH. The Integrated Biological Imaging Facility, supported by the Creighton University Medical School, was constructed with support from C06 Grant RR17417-01 from the NCRR, NIH. We thank Tom Bargar at the University of Nebraska Medical Center for assistance in scanning electron microscopy.

Correspondence should be addressed to David Z.Z. He, Department of Biomedical Sciences, Creighton University School of Medicine, 2500 California Plaza, 0maha, NE 68178, Tel: 402280 1409, E-mail: hed@creighton.edu; Shiming Yang, Department of Otolaryngology, Institute of Otolaryngology, 301 Hospital, 28 Fuxing Road, Beijing 100853, People's Republic of China, Tel: 8610 6693-6752. E-mail: yangsm301@263.net.

DOI:10.1523/JNEUROSCI.3231-09.2009

Copyright $\odot 2009$ Society for Neuroscience 0270-6474/09/2915277-09\$15.00/0 slow adaptation of mechanotransduction (Gillespie and Corey, 1997; Holt et al., 2002).

The hair bundles are susceptible to acoustic trauma and ototoxic drugs. It has been shown that the damaged hair cells can undergo intracellular repair (Sobkowicz et al., 1996; Zheng et al., 1999). Spontaneous hair-bundle repair is well documented in chick and frog hair cells (Baird et al., 1996, 2000; Gale et al., 2002). In organ cultures of the bullfrog saccule, hair cells that lost their hair bundles as a result of sublethal antibiotic treatment survived as bundleless cells for at least 1 week (Gale et al., 2002). New hair bundles emerge between 4 and $7 \mathrm{~d}$ in the absence of mitosis. Utricular hair cells from neonatal rodents can also survive gentamicin insult and regrow their stereocilia in culture after stereociliary loss (Zheng et al., 1999). It is unknown, however, whether cochlear hair cells could survive stereociliary loss and whether the lost hair bundles could be regenerated.

The transduction apparatuses of hair cells are occasionally exposed to intense sound that can break tip links (Pickles et al., 1987). The susceptibility of tip links to acoustic trauma raises the question of whether these delicate tip links can self-repair. The tip links of chick hair cells are able to self-repair in several hours after they are severed (Zhao et al., 1996). However, it has not been determined whether mammalian cochlear hair cells also retain the self-repair capability.

Organotypic culture of the organ of Corti of newborn gerbils has been used to study the functional maturation of outer hair cells (OHCs) and their relation to innervation (He, 1997; He et al., 2001). These and other studies (Rüsch et al., 1998; Waguespack et al., 2007) demonstrate that the culture environment and denervation do not alter hair cell development. In this study, we simulated acoustic trauma-induced tip-link damage or 
stereociliary loss by disrupting the tip links or by ablating the hair bundles in the culture preparation. Our goals were to determine whether cochlear hair cells could survive the trauma and whether the tip link and/or the hair bundle could be spontaneously repaired.

\section{Materials and Methods}

Care and use of the animals in this study were approved by grants from the National Institutes of Health and by the Institutional Animal Care and Use Committee of Creighton University.

Tissue culture of the organ of Corti. Newborn gerbils were used for all the experiments. Births in the gerbil breeding colonies were monitored at 9:00 A.M. and 5:00 P.M. daily. Explantations were performed on the day of birth and designated as $0 \mathrm{~d}$ in culture. A detailed description has been given previously (He, 1997). In brief, newborn gerbil pups were given a lethal dose of sodium pentobarbital (200 mg/kg, i.p.). After the skin was cleaned with $75 \%$ alcohol, the animals were decapitated, and the cochleae were dissected out and kept in cold L-15 (Invitrogen). The basilar membrane and the associated organ of Corti were carefully unwrapped from the modiolus. The whole basilar membrane and organ of Corti were cut into three segments (apical, middle, and basal). The segment was then explanted onto plastic or glass coverslips placed on the bottom of culture dishes containing $1.2 \mathrm{ml}$ of DMEM. The tissue was oriented with the ciliated pole of hair cells pointing upward. After $\sim 1 \mathrm{~h}$ incubation, $15 \%$ (by volume) of heatinactivated fetal bovine serum, $2 \%$ of $\mathrm{B}-27$, and $1 \%$ of $\mathrm{N}-2$ supplements (all from Invitrogen) were added to the dish. The cultures were then maintained in a $37^{\circ} \mathrm{C}$ incubator (Sanyo Model MCO-17A) with $5 \% \mathrm{CO}_{2}$. The culture medium was replaced every other day.

Recording mechanotransducer current and nonlinear capacitance. Recording mechanotransducer (MET) current from cultured OHCs was essentially the same as recording from freshly isolated cochlear segments. The details have been described previously (Jia and He, 2005). The external solution for most experiments was L-15. Its inorganic components (in mM) were as follows: $\mathrm{NaCl}, 136 ; \mathrm{NaH}_{2} \mathrm{PO}_{4}, 5.8 ; \mathrm{KCl}, 5.4 ; \mathrm{CaCl}_{2}, 1.3$; $\mathrm{MgCl}_{2}, 0.9$; and $\mathrm{MgSO}_{4}, 0.4$. The solution was buffered with $10 \mathrm{~mm}$ HEPES, the $\mathrm{pH}$ was adjusted to 7.4 , and osmolarity was $300 \mathrm{mOsm}$. The patch electrodes were backfilled with our standard internal solution, which contained the following (in mM): $\mathrm{CsCl}, 140 ; \mathrm{CaCl}_{2}, 0.1 ; \mathrm{MgCl}_{2}, 3.5$; MgATP, 2.5; EGTA-KOH, 5; and HEPES-KOH, 10. The solution was adjusted to $\mathrm{pH} 7.4$ with Trizma Base (Sigma) and osmolarity adjusted to $300 \mathrm{mOsm}$ with glucose. The pipettes had initial bath resistances of $\sim 2-4 \mathrm{M} \Omega$. Access resistances were typically from 6 to $10 \mathrm{M} \Omega$. After the whole-cell configuration was established and series resistance was $\sim 70 \%$ compensated, the cell was held under voltage-clamp mode to record MET currents in response to bundle deflection by a fluid jet positioned $\sim 10-15 \mu \mathrm{m}$ away from the bundle. Sinusoidal bursts $(100 \mathrm{~Hz})$ with different magnitudes were used to drive the fluid jet as described previously (Kros et al., 1992; Holt et al., 1997; Jia and He, 2005). Holding potential was normally set near $-70 \mathrm{mV}$. The currents (filtered at $2 \mathrm{kHz}$ ) were amplified using an Axopatch 200B amplifier (Invitrogen). Currents were acquired by software pClamp 9.1 (Invitrogen) running on an IBMcompatible computer with a 16 bit analog-to-digital converter (Digidata $1322 \mathrm{~B})$. The sampling frequency was $20 \mathrm{kHz}$. When fast adaptation of the MET current was to be determined, a rigid glass fiber $(\sim 5-6 \mu \mathrm{m}$ in tip diameter) was used to deflect the bundle. The fiber motion was driven by a piezoelectric actuator (Burleigh Driver/Amplifier, PZ-150M). Step- voltage commands generated by a function generator were low-pass filtered at $4.5 \mathrm{kHz}$ before being fed to the piezoelectric actuator. The rise time (between $10 \%$ and $90 \%$ of steady-state value) of paddle motion was $\sim 90-100 \mu \mathrm{s}$, corresponding to a cutoff frequency of $3.8-3.5 \mathrm{kHz}$. MET currents were sampled at $100 \mathrm{kHz}$ and filtered at $5 \mathrm{kHz}$. Three presentations were averaged for each trial. Data were analyzed using Clampfit in the pClamp software package (Invitrogen) and Igor Pro (WaveMetrics).

For nonlinear capacitance (NLC) measurements, the culture was bathed in extracellular solution containing the following (in $\mathrm{mM}$ ): $\mathrm{NaCl}$, 120; TEA-Cl, 20; $\mathrm{CoCl}_{2}, 2 ; \mathrm{MgCl}_{2}, 2$; HEPES, 10; and glucose, 5 at pH 7.4. The internal solution contained the following (in mM): $\mathrm{CsCl}, 140 ; \mathrm{MgCl}_{2}$, 2; EGTA, 10; and HEPES, 10 at $\mathrm{pH}$ 7.4. The two-sine voltage stimulus protocol $(10 \mathrm{mV}$ peak at both 390.6 and $781.2 \mathrm{~Hz})$ with subsequent fast Fourier transform-based admittance analysis (jClamp, version 14.1) was used to measure membrane capacitance (Santos-Sacchi et al., 2001). NLC data were acquired using jClamp software (Scisoft). Fits to the capacitance data were made in IgorPro (WaveMetrics). The maximum charge transferred through the membrane's electric field $\left(Q_{\max }\right)$, the slope factor of the voltage dependence $(\alpha)$, the voltage at peak capacitance $\left(V_{\mathrm{pkcm}}\right)$, and the linear membrane capacitance $\left(C_{\mathrm{lin}}\right)$ were determined. The charge density $\left(Q_{\max } / C_{\text {lin }}\right)$ was used to normalize for cell size to compare the prestin expression level during development (Oliver and Fakler, 1999).

Immunocytochemistry and scanning electron microscopy. Cultures were perfused with $4 \%$ formaldehyde in phosphate buffer. After 30 min of fixation, the tissues were treated with $0.2 \%$ Triton X-100/PBS. Goat serum $(10 \%)$ was used to block nonspecific binding. The tissue was then incubated with anti-C-mPres antibody (S3) (Liberman et al., 2002). The samples were washed with PBS, followed by incubation with secondary antibodies. After washed with PBS, the samples were mounted on glass slides with antifade solution (Prolong Antifade Kit, Invitrogen). To visualize the stereocilia, actin in stereocilia was labeled with rhodaminephalloidin, as described previously (Belyantseva et al., 2003). The samples were examined using a LSM 510 META confocal scanning sys- 


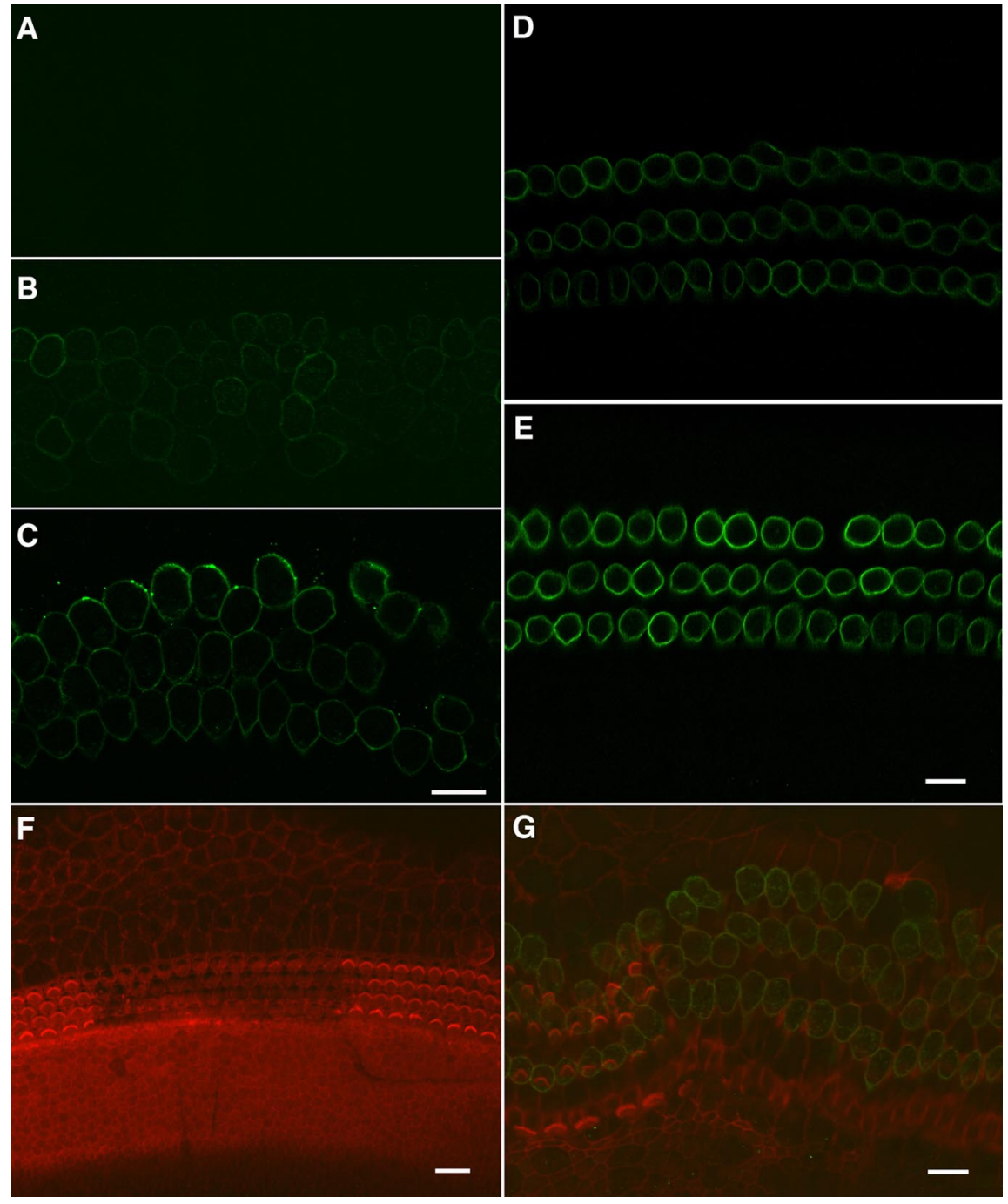

Figure 2. Confocal images of prestin expression in the $\mathrm{OHCS.A,} \mathrm{One} \mathrm{day} \mathrm{after} \mathrm{the} \mathrm{hair} \mathrm{bundles} \mathrm{were} \mathrm{removed.} \mathrm{No} \mathrm{prestin}$ immunoactivity was seen at this age. $\boldsymbol{B}, \boldsymbol{C}$, Six and eleven days after the bundles were removed. Prestin was expressed at 6 PID and strongly expressed at 11 PID. Scale bar: $10 \mu \mathrm{m}$ for $\boldsymbol{A}-\boldsymbol{C}$. D, E, Prestin expression in the preparations isolated from the developing gerbils at $7(\boldsymbol{D})$ and $12(\boldsymbol{E}) \mathrm{d}$ after birth. Both were from middle turns. $\boldsymbol{F}, \boldsymbol{G}$, Hair bundles and prestin expression at 1 PID. The hair bundle was labeled with rhodamine-phalloidin. Three rows of "V"-shaped OHC bundles and one row of IHC bundles could clearly be seen in the control areas. The hair bundles were no longer present in the area (middle of the image) where the hair bundles were removed. No prestin immunoactivity was seen at this age. G, Hair bundles and prestin expression at 11 PID. The hair cell region expanded significantly at this age. Prestin immunoactivity could be seen in the OHCs with and without the hair bundles.

tem with three lasers mounted on a Zeiss AxioPlan 2IE MOT motorized upright microscope (Carl Zeiss International).

For scanning electron microscopy (SEM), the organ cultures were fixed for $15 \mathrm{~min}$ with $2.5 \%$ glutaraldehyde in $0.1 \mathrm{M}$ sodium cacodylate buffer, $\mathrm{pH} 7.4$, containing $2 \mathrm{mM} \mathrm{CaCl}_{2}$, washed in PBS, and then postfixed for 10 min with $1 \% \mathrm{OsO}_{4}$ in the same buffer and washed. The tissues were dehydrated via an ethanol series, critical point dried from $\mathrm{CO}_{2}$ and sputter-coated with gold. The tissue was then examined using a FEI Quanta 200 scanning electron microscope (FEI).

\section{Results}

\section{Fate of hair cells after loss of their stereocilia}

Cultures were prepared from the middle and basal turns of the cochleae from newborn gerbils. Figure $1 A$ shows a survey micrograph of a typical 1-d-old culture of the basilar membrane-organ of Corti from the basal turn. Under low magnification $(10 \times)$ and with the help of a Narashige micromanipulator (MHW-3, Narashige International USA), three thin glass fibers were in- serted between the tissue and the coverslip to mark the area where the hair bundles would be removed and the area used for control (Fig. 1B). Marking the areas allowed us to locate the damaged area for subsequent observations and comparison. The fibers, $\sim 4-10 \mu \mathrm{m}$ in diameter, were fabricated in the same way as those used to measure the stiffness of OHCs ( $\mathrm{He}$ and Dallos, 1999). Each area was $\sim 90-$ $120 \mu \mathrm{m}$ in width and contained $\sim 30-45$ OHCs and 10-14 inner hair cells (IHCs). After the areas were marked, we removed the hair bundles under high magnification $(63 \times$ water-immersion objective with NA of 0.9). Under bright field illumination, the "V"-shaped stereocilia bundle of OHCs was clearly seen (Fig. 1C). We disrupted and removed the hair bundles by scrubbing a suction pipette on the reticular lamina with the help of the Narashige micromanipulator and by gentle suction of the damaged stereocilia into the pipette (tip diameter of 5-6 $\mu \mathrm{m}$ ). Figure 1, $C$ and $D$, shows two representative images taken before and during the procedure. The procedure was performed $\sim 24 \mathrm{~h}$ after the tissue was explanted in culture. The purpose of this $24 \mathrm{~h}$ period before bundle ablation was to allow the tissue to grow and to stick to the coverslip. After the bundle was removed, the tissues were kept in the $\mathrm{CO}_{2}$ incubator for recovery. We used the postinjury day (PID) throughout the text to describe the age of the culture. The actual age of the culture was $1 \mathrm{~d}$ older than the PID.

Prestin immunoreactivity (Zheng et al., 2000) combined with confocal microscopy was used to examine the fate of bundleless hair cells. Prestin is virtually undetectable in the lateral membrane of $\mathrm{OHCs}$ in the first few days after birth. The most prominent increase in label intensity occurs between 6 and $9 \mathrm{~d}$ after birth (Belyantseva et al., 2000). Therefore, development of prestin immunoreactivity can be used as an assay to probe the status of $\mathrm{OHC}$ development. Absence of staining would suggest cell death or developmental delay. Prestin expression was examined at 1, 6, and 11 PID. Figure 2 shows three representative confocal images of normal and bundleless OHCs at 1, 6, and 11 PID. No prestin expression was detected at 1 PID (Fig. $2 A$ ), while weak prestin expression was detected at 6 PID (Fig. $2 B$ ) and strong expression was seen at 11 PID (Fig. 2C). Figure 2, $D$ and $E$, shows prestin immunoreactivity of noncultured $\mathrm{OHCs}$ dissected from developing gerbils at 7 and $12 \mathrm{~d}$ after birth for comparison. As shown, the development of prestin immunoactivity was similar. To further confirm that bundleless OHCs could survive and develop, we labeled the stereociliary bundles with rhodaminephalloidin and prestin with a prestin antibody in the same cultures. Figure 2, $F$ and $G$, exhibits two confocal images obtained from cultures at 1 and 11 PID. To facilitate comparison, we acquired images containing areas with and without bundle loss. In 
Figure $2 \mathrm{~F}$, the $\mathrm{V}$-shaped hair bundles were clearly seen in the control area, while in the damaged area, stereociliary bundles were no longer present. No prestin immunoactivity was detected at this age (1 PID). At $11 \mathrm{PID}$, three rows of OHC stereociliary bundles and one row of IHC bundles were visible in the control area. In the damaged area, stereociliary bundles were not present. However, strong prestin expression could be seen in both damaged and control areas. One would also notice that there was a significant expansion of the hair cell area (Fig. 2G). This was common during the later stage of culturing, and possible reasons were discussed by Sobkowicz et al. (1993) and by He (1997). Because hair cell death also occurred under normal conditions in culture (Sobkowicz et al., 1993; He, 1997), we counted the total number of hair cells in the control and damaged areas to determine the survival rate of bundleless OHCs at 6 and 11 PID. The survival rate of bundleless hair cells after normalizing to the hair cells in the control area was $84 \pm 12 \%(n=8$ cultures $)$ and $71 \pm$ $17 \%(n=11)$ at 6 and 11 PID.

To further determine the fate of bundleless OHCs, we examined the maturation of NLC (Ashmore, 1989; Santos-Sacchi, 1989), an electrical signature of electromotility. The onset of electromotility occurs at $\sim 7 \mathrm{~d}$ after birth in vivo and in culture (He et al., 1994; He, 1997). Small NLC can be detected as early as $3 \mathrm{~d}$ after birth (Oliver and Fakler, 1999; Belyantseva et al., 2000). The magnitude of NLC increases until adult-like responses are reached at 13-14 d (Oliver and Fakler, 1999; Belyantseva et al., 2000). We measured NLC from the bundleless OHCs at 4 and 11 PID. Figure $3 A$ shows two examples from those measurements. The magnitude of NLC was small at 4 PID and became significantly larger at 11 PID. We measured six cells from each age group and compared the ratio of $Q_{\max } / C_{\operatorname{lin}}$ at 4 and 11 PID. The ratio was significantly greater at 11 PID than at 4 PID $(p<0.01$, Student's $t$ test), suggesting the functional maturation of bundleless OHCs.

Because there are no specific chemical markers to probe the status of IHCs, we measured the whole-cell current from the bundleless IHCs to determine their fate. Previous studies showed developmental changes in the expression of a number of ionic currents in IHCs between birth and the onset of hearing (Kros et al., 1998; Marcotti et al., 2003). Since the $\mathrm{K}^{+}$currents increased significantly between birth and onset of hearing (Marcotti et al., 2003), we compared the magnitude of $\mathrm{K}^{+}$currents at 4 and 11 PID. As the two examples show in Figure $3 B$, the magnitude and activation rate of $\mathrm{K}^{+}$currents increased significantly between 4 and 11 PID. The increase in the magnitude and activation rate of $\mathrm{K}^{+}$currents suggests that bundleless IHCs not only survived but also underwent functional development.

\section{Fate of hair bundles}

To determine whether truncated hair bundles could self-repair, we examined the apical surface of hair cells using SEM. Figure 4, $A$ and $D$, shows two examples of SEM pictures of the damaged and undamaged areas at 7 and 13 PID at low magnification. High-magnification images of the cuticular plate of an OHC and an IHC with a truncated bundle from the damaged area at 7 PID are presented in Figure 4, $B$ and $C$. One apparent feature in the two images is that the rootlets of truncated stereocilia remained in the cuticular plate. However, no regrowth or elongation of the truncated stereocilia was seen in either type of hair cells, despite the fact that the kinocilia and some microvilli were still visible. We examined 307 OHCs and 98 IHCs from six cultures. None of them showed any sign of regrowth or elongation of the stereocilia at 7 PID. We examined the status of stereocilia from seven cul-
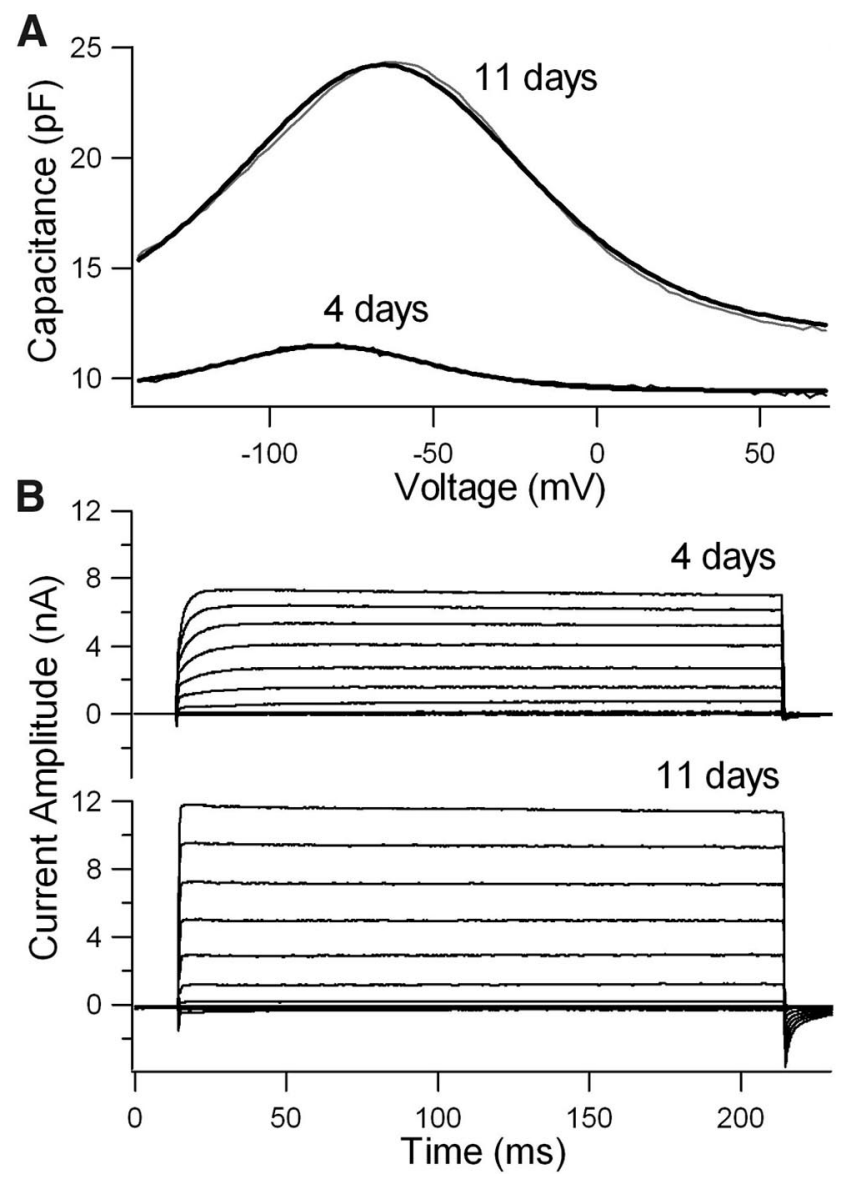

Figure 3. NLC and whole-cell currents recorded from bundleless OHCs and IHCs. $\boldsymbol{A}, \mathrm{NLC}$ measured from two representative $\mathrm{OHCs} 4$ and $11 \mathrm{~d}$ after their hair bundles were ablated. The cells were held at $0 \mathrm{mV}$ and two-sinusoidal voltage protocols were used to probe voltagedependent NLC. NLC was plotted in black thin lines while the Boltzmann function used to fit the response was in heavy black lines. $\boldsymbol{B}$, Whole-cell currents measured from two representative IHCs in cultures 4 and $11 \mathrm{~d}$ after their hair bundles were removed. The cells were held at -70 $\mathrm{mV}$. The membrane potential varied from -120 to $80 \mathrm{mV}$ in $20 \mathrm{mV}$ steps.

tures at 13 PID. Two high-magnification images are shown in Figure 4, $E$ and $F$. While signs of remaining rootlets in the cuticular plate were partially visible in both types of hair cells, the cuticular plate remained flat. We examined 289 OHCs and 103 IHCs at this age. No signs of repair or elongation of the truncated stereocilia were observed in any of the cultures examined. Unlike the apical surface shown in Figure 4, $B$ and $C$, the kinocilia and microvilli were no longer present at 13 PID, a sign of development of hair cells (Furness et al., 1989; Goodyear et al., 2005; Waguespack et al., 2007). The presence of stereociliary rootlets in the cuticular plate corroborates the immunocytochemical evidence that the hair cells could survive the trauma $13 \mathrm{~d}$ after the bundles were removed.

The kinocilium has been proposed to play an important role in hair-bundle elongation and the staircase-like organization during development [for review, see Tilney et al. (1992) and Nayak et al. (2007)] and that microvilli may act as an elementary "building block" for the assembly of the hair bundles (Gorelik et al., 2003). Neonatal hair cells possess kinocilia and abundant microvilli as shown in Figure $5 A$ from a 2 -d-old culture (from the middle turn). Kinocilia and microvilli disappear during development (Furness et al., 1989; Goodyear et al., 2005) as demonstrated in Figure $5 B$, which was obtained from the undamaged 

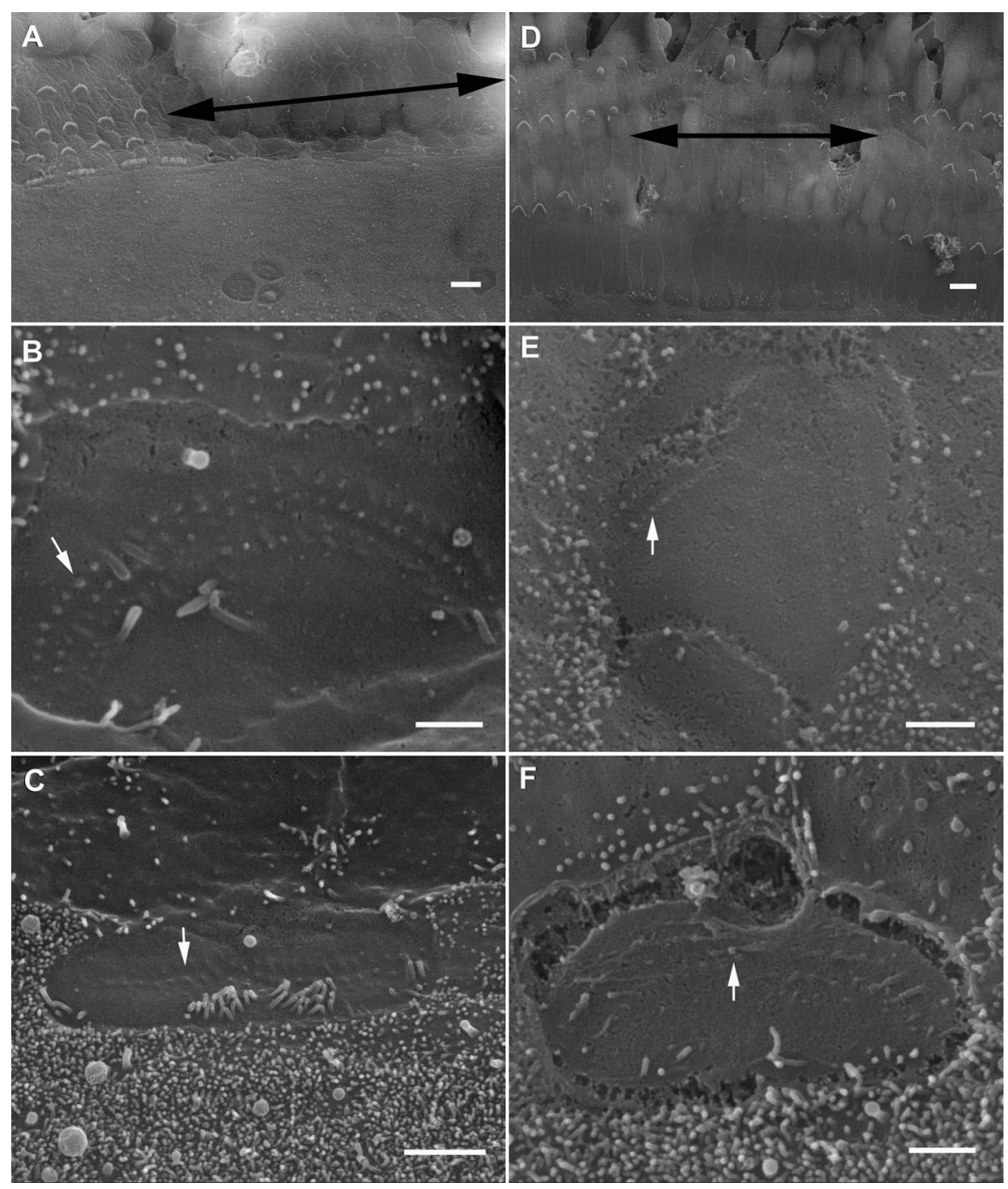

Figure 4. SEM pictures of cultured organ of Corti and hair cell stereocilia. $A$, Surface view of the reticular lamina at 7 PID The area where the bundle was removed is marked by double-head arrows. The tissue was from the middle turn. No regrowth or elongation of the truncated stereocilia was seen. $\boldsymbol{B}$, Apical surface of a bundleless $\mathrm{OHC}$ under high magnification. The rootlets of three rows of truncated stereocilia were clearly visible. A white arrow indicates one of the rootlets. A kinocilium is still present in the apical surface. $C$, A bundleless IHC. Some microvilli together with a kinocilium are also seen. $\boldsymbol{B}$ and $\boldsymbol{C}$ are both from the damaged area from $\boldsymbol{A}$. D, Surface view of the reticular lamina at 13 PID. No bundle repair was observed. The tissue was from basal turn. $\boldsymbol{E}, \boldsymbol{F}$, High-magnification images of the apical surface of an $0 \mathrm{HC}(\boldsymbol{E})$ and IHC $(\boldsymbol{F})$. Arrows mark the rootlets of stereocilia. $\boldsymbol{E}$ and $\boldsymbol{F}$ are from the damaged area shown in $\boldsymbol{D}$. Scale bars in $\boldsymbol{A}$ and $\boldsymbol{D}$ represent 10 $\mu \mathrm{m}$, while the bars in the rest of the images represent $1 \mu \mathrm{m}$.

area in a 13 PID preparation. Because of the potential role of kinocilia and microvilli for stereociliary development and for possible stereociliary replacement, we questioned whether the presence of kinocilia could promote regrowth of the truncated stereocilia and whether regrowth could actually come from the microvilli. The fine-controlled suction technique allowed us to remove the stereocilia while maintaining the kinocilium and/or microvilli in the apical surface. As the example shows in Figure $5 C$, the kinocilium remained while the stereociliary bundle was removed. We examined six cells from two cultures, and no regrowth or repair of the stereocilia was observed at any cells under such conditions at 7 PID (Fig. $5 C$ ). We then removed one side of the "V"-shaped stereocilia to determine whether the remaining stereocilia would initiate elongation of the truncated stereocilia in seven OHCs examined from two cultures. As is apparent from Figure 5D, no sign of any regrowth was seen at any OHCs at 7 PID.

\section{Self repair of tip links}

The tip link is particularly vulnerable to intense noise exposure. In chick hair cells, the broken tip links can be self-repaired (Zhao et al., 1996). We questioned whether the tip links of mammalian hair cells could self-repair after they are cut. Since hair cells in the first week after birth have abundant side links (Furness et al., 1989; Waguespack et al., 2007), which might complicate the process of breaking the tip links, we dissected out the cochlea from 8-d-old gerbils for all the experiments described below. At this stage of development, the morphology of stereocilia approaches adult-looking, and mechanotransduction also shows adult-like response (Waguespack et al., 2007). An SEM image obtained from a preparation that was dissected out from the apical turn at $8 \mathrm{~d}$ after birth and cultured for $24 \mathrm{~h}$ is presented in Figure $6 \mathrm{~A}$. As shown, the kinocilia in some hair cells already disappeared (marked by a small white arrow), while in other hair cells, the kinocilia was significantly shorter (small black arrow) and in the process of being absorbed.

In all experiments described below, we only used cultures prepared from the cochlear apical turn for experiments. The hair bundle in the apical turn OHCs is $\sim 5$ $\mu \mathrm{m}$ in height (as opposed to $\sim 3 \mu \mathrm{m}$ in the basal turn). This allowed us to mechanically stimulate the hair bundle effectively with the techniques we used. To break the tip link, the apical turn was incubated in the $\mathrm{Ca}^{2+}$-free medium with $5 \mathrm{~mm}$ BAPTA for $20 \mathrm{~min}$ as previously described (Zhao et al., 1996). A number of studies have shown that treatment with calcium chelators entirely abolishes transduction (Assad et al., 1991; Crawford et al., 1991; Zhao et al., 1996; Ricci et al., 2003). After wash out, the BAPTA-treated and untreated (control) tissues were incubated for $24 \mathrm{~h}$ in the normal media (DMEM with $2 \mathrm{~mm}$ $\mathrm{Ca}^{2+}$ and $15 \%$ serum) under conditions described for the experiments above. If tip links are gating springs, regeneration of tip links should restore mechanoelectrical transduction. We recorded MET currents from IHCs and OHCs after BAPTA treatment to verify that the tip links were indeed broken. The fluid jet technique (Kros et al., 1992; Holt et al., 1997; Jia and He, 2005) was used to deflect the hair bundle. The cells were held at -70 $\mathrm{mV}$. We used a large sinusoidal stimulus to deflect the bundle so that the saturated response could be obtained for comparison between different groups. We recorded MET current from five $\mathrm{OHCs}$ and five IHCs from the BAPTA-treated groups (four cultures) within 30 min after the BAPTA treatment was completed. None of the cells measured showed any bundle-deflectionevoked MET current. Two examples of the lack of MET current are presented in Figure 6, $C$ and F. After a $24 \mathrm{~h}$ incubation for recovery, we recorded MET current from the BAPTA-treated (recovered) hair cells. Two examples are showed in Figure 6, D 
and G. Robust MET currents could be seen in both types of the hair cells. The reappearance of the MET current was supported by the reemergence of tip links. Figure $6 B$ shows an example of an SEM picture of the regenerated tip links $24 \mathrm{~h}$ after the tip links were cut. We also recorded MET current from the control (non-BAPTA-treated) hair cells. As shown in Figure 6, $E$ and $H$, larger MET currents could be evoked, similar to that seen in a previous study (Jia and He, 2005). We compared the magnitude of MET current between seven recovered ( $n=5$ cultures) and six control ( $n=4$ cultures) OHCs. The magnitude of the recovered OHCs was $72 \pm 11 \%$ of the control group. For the IHCs, the magnitude was $63 \pm 10 \%$ of the controlled group ( $n=5$ for both groups). Despite the fact that the magnitude of MET currents were still significantly less than the control group, reappearance of the MET current $24 \mathrm{~h}$ after the tip links were eradicated strongly suggests that the majority of the tip links have been self-repaired.

We also examined adaptation of the MET current from the recovered OHCs to determine whether the regenerated tip links could mediate adaptation. A rigid fiber technique and step voltage stimulation were used to deflect the hair bundle, as described by Kennedy et al. (2003) and Ricci et al. (2005). Since the rise time of the paddle motion to deflect the hair bundle was $\sim 90-100 \mu \mathrm{s}$, corresponding to a cutoff frequency of $\sim 3.8-3.5 \mathrm{kHz}$, it was not fast enough to accurately measure the rate of fast adaptation in the middle and basal turn OHCs. For this reason, we only measured adaptation of MET current from the apical turn OHCs. However, we assumed if the regenerated tip links in the apical turn OHCs would mediate adaptation, the regenerated tip links of any hair cells at any cochlear locations would have the same capacity. Figure 6, I and J, shows two examples obtained from the recovered and control OHCs. As shown, the MET current exhibited rapid activation followed by rapid decline. We measured fast adaptation of the MET current from $5 \mathrm{OHCs}$ from the recovered group at a low level of stimulation. The MET current response at the lowest stimulation level was fitted with a single exponential to estimate the time constant for fast adaptation. The mean value of the rate of fast adaptation was $148 \pm 25 \mu \mathrm{s}$, while that of the controlled group was $123 \pm 18 \mu \mathrm{s}(n=4)$. Although the rate of fast adaptation of the recovered OHCs is slower than the control group, the presence of fast adaptation in the MET current demonstrates that important functional features of the transduction apparatus are restored in the regenerated tip links.

\section{Discussion}

We took the advantage of long-term culture of the organ of Corti and the techniques to ablate the stereocilia and to monitor postinjury response over time to address four basic questions that are important for understanding the cell biology of hair cell repair and apical specialization: Can mammalian cochlear hair cells sur- vive after loss of their apical specialization, the hair bundle? How long can the bundleless hair cells survive? Can the truncated hair bundles self-repair? Can the tip links self-repair when broken? We showed that neonatal IHCs and OHCs could not only survive but also develop for $\sim 2$ weeks in vitro after their stereocilia were removed. However, neither type of the hair cells was able to repair their lost stereocilia within 2 weeks. In cultured rat utricles, a substantial number of hair cells can survive gentamicin insult after their stereocilia are lost. The damaged hair cells can survive and regrow their stereocilia in a week (Zheng et al., 1999). The inability of auditory hair cells to self-repair their lost bundles appeared to be different from the vestibular hair cells, despite the fact that the culture environment was essentially identical. This is also in contrast to the study done by Sobkowicz et al. (1992, 1996), who showed that neonatal auditory hair cells also have the ability to survive and repair their stereocilia following mechanical injury in organotypic cultures. However, we strongly believe that the technique used by Sobkowicz et al. $(1992,1996)$ could not have ablated the hair bundle. There are three reasons: First, the stereocilia of neonatal hair cells have abundant side links and extracellular matrix (Russell and Richardson, 1987; Goodyear et al., 2005; Waguespack et al., 2007), and are extremely resilient to mechanical insult, as we demonstrated in supplemental Video 1 (available at www.jneurosci.org as supplemental material). Sec- 


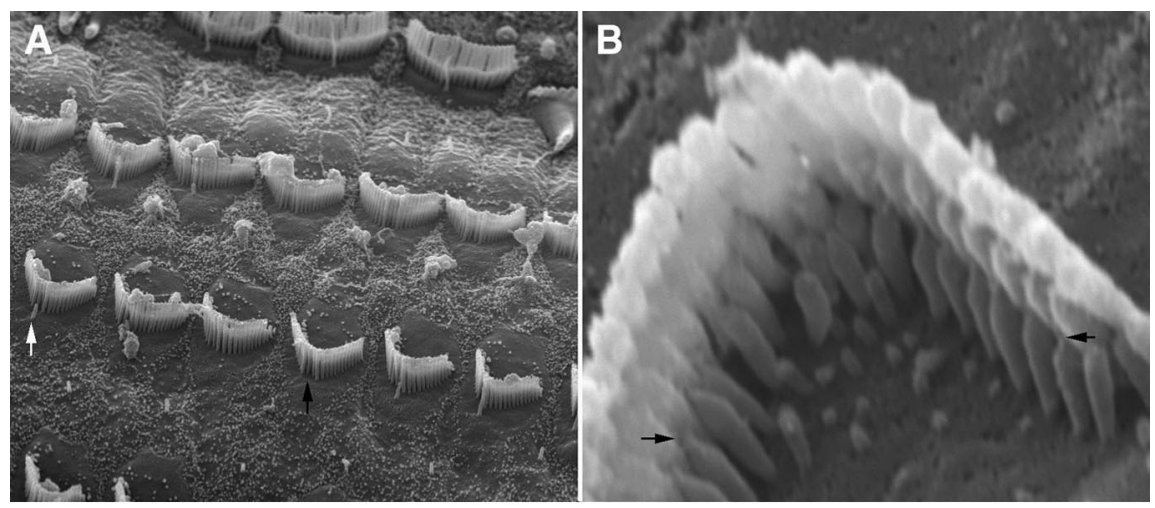

IHCs

C

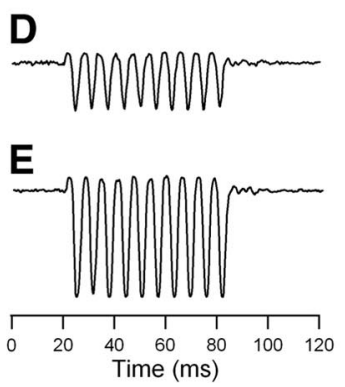

OHCs

$\mathbf{F}$

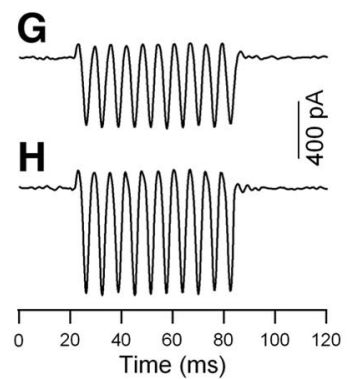

I

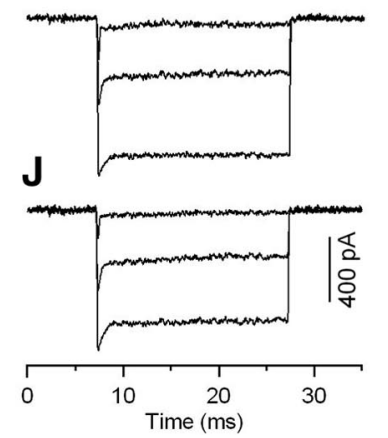

Figure 6. SEM picture of hair cell stereocilia and the MET currents measured from cultured hair cells. All cultures were prepared from the cochlear apical turn from 8-d-old gerbils for all experiments. A, SEM of stereociliary bundles after cultured for $24 \mathrm{~h}$. At this age, the kinocilium in some hair cells already disappeared (indicated by a black arrow) and in other hair cells, the kinocilium was still present (marked by a white arrow). $\boldsymbol{B}$, Newly regenerated tip links $24 \mathrm{~h}$ after being cut. Tip links could clearly be seen in the apex of the innermost (shortest) stereocilia to the side of their taller neighbor. Two black arrows mark the two examples of the newly regenerated tip link. $\boldsymbol{C}, \boldsymbol{F}, \mathrm{MET}$ current recorded $10 \mathrm{~min}$ after BAPTA treatment. $\boldsymbol{E}, \boldsymbol{F}$, MET current recorded from control IHC and $\mathrm{OHC}$ after $24 \mathrm{~h}$ culture. D, G, MET current returned in the BAPTA-treated preparations after $24 \mathrm{~h}$ culture. The cells were held at $-70 \mathrm{mV}$. The bundle was vibrated in response to fluid jet stimulation at $100 \mathrm{~Hz}$. Three presentations were averaged for each trial. $\boldsymbol{E}, \boldsymbol{H}, \mathrm{MET}$ currents measured from cultured hair cells whose tip links were not cut (control group). $I, J$, Adaptation of MET currents measured from control $(\boldsymbol{I})$ and BAPTA-treated $(\boldsymbol{J}) \mathrm{OHCs}$ after $24 \mathrm{~h}$ culturing. The hair bundle was deflected by a rigid fiber which was driven by piezoelectric actuator. Three presentations were averaged for each trial.

ond, it was absolutely impossible to ablate the stereocilia under a dissecting scope with a hand-held pipette (tip diameter of 100 $\mu \mathrm{m})$ because the hair bundles could not be visualized and the pipette movement could not be precisely controlled. Finally, Sobkowicz et al. $(1992,1996)$ did not verify that the bundles were indeed removed. Nor did they mention how the area of damage was labeled and monitored for later observation. We strongly believe the "self-repaired" hair bundles that Sobkowicz et al. $(1992,1996)$ observed were just the undamaged hair bundles. The suction pipette technique to denude the hair cells under high magnification with precise control was demonstrated in supplemental Video 2 (available at www.jneurosci.org as supplemental material). With this approach, the destruction of stereocilia was complete and could be directly visualized and confirmed during the procedure.

It is important to justify the use of a neonatal culture preparation for the experiments. The culture conditions are different from an in vivo environment, and neonatal hair cells are different from adult hair cells. However, tissue culture has a unique advantage over the in vivo animal models. The advantage is that the damage to the bundle can be controlled and well defined, and morphological changes in the hair bundle and soma can easily be monitored during the recovery process. In animal models, the extent and severity of damage vary significantly at different co- chlear locations, and from animal to animal after exposure to noise or ototoxic drugs. That makes damage to the bundle difficult to control and compare over time. A better model would be long-term culture of adult hair cells. However, adult hair cells are able to survive for only a few hours in a culture environment. Nevertheless, if neonatal hair cells cannot even regenerate their hair bundles, the adult hair cells are more unlikely to be able to do so.

Neither IHCs nor OHCs were able to repair their lost stereocilia in culture within a period of $\sim 2$ weeks. It is important to discuss the possibility of self-repair or regeneration that may take longer than 2 weeks. The following reasons argue against such possibility. The first reason is based on comparison. Stereocilia regeneration in frog and bird hair cells and in mammalian vestibular hair cells occurs in a few days in culture (Baird et al., 1996, 2000; Zheng et al., 1999; Gale et al., 2002). We would expect to see at least some signs of repair or regeneration within a period of 2 weeks if the cochlear hair cells had retained that capacity. Such signs may include slight elongation of the truncated stereocilia, and/or elongation of the microvilli. As our SEM pictures show in Figures 4 and 5 , no such signs were observed under all the conditions we manipulated. The second reason is based on the time course of the development of hair bundles. The appearance and elongation of stereocilia during development occurs in less than a week (Tilney et al., 1992; Nayak et al., 2007). Since most regeneration follows a similar process and time course during development [for review, see Holley (2002) and Baker et al. (2009)], we would expect to see some signs of repair or regeneration of the stereocilia within 2 weeks. The last reason is based on the rate of actin renewal in the stereocilia of neonatal hair cells. Repair of the truncated stereocilia and/or regeneration of the stereocilia from microvilli would need actin for elongation of cilia. The structure and length of the hair bundle are dynamically maintained by regulating the turnover of the actin filaments. Transfecting cultured hair cells with GFP-labeled $\beta$-actin shows that actin monomers are constantly being added at the tips of the stereocilia, moving down along each filament, and finally dissociating at its bottom end in a process described as treadmilling (Schneider et al., 2002; Rzadzinska et al., 2004). The time course of this renewal process in cultured hair cells is $\sim 2 \mathrm{~d}$. Based on the actin renewal rate, we would expect to see some signs of repair after a few days. Collectively, all these reasons suggest that it is unlikely that regeneration of the bundle would take longer than 2 weeks to emerge.

It is interesting that neonatal hair cells can survive for $\sim 2$ weeks after loss of their stereocilia, the apical specialization that is unique to hair cells. The mechanotransduction channels are already functional at this age (Géléoc and Holt, 2003; Waguespack et al., 2007). But the majority of the transduction channels remain closed since the culture medium contains $1.3 \mathrm{~mm}$ calcium 
and since there is no load on the hair bundle (Kros et al., 1992; He et al., 2004; Jia et al., 2007). It is not clear how the absence of a small standing current (Ricci et al., 2002) from a fraction of opened transduction channels would affect the condition of the hair cells. However, it appears that the hair bundle and its associated mechanotransduction have no immediate effect on the survival of neonatal hair cells. It is also interesting that cochlear hair cells are not able to regenerate their lost hair bundles, while their counterpart, the vestibular hair cell, is. Nevertheless, this is not entirely surprising since mammalian vestibular system also retains some capacity to regenerate the lost hair cells (Forge et al., 1993; Warchol et al., 1993). Apparently, the genes that are related to repair and regeneration in the cochlear hair cells are either absent or downregulated and cannot be activated by the injury signals.

While there is no evidence that the hair bundle can be regenerated, the tip links of IHCs and OHCs appeared to have the capacity to self-repair after being broken by the calcium chelator, BAPTA. Repair of tip links was evident by the restoration of mechanoelectrical transduction (Fig. 6). This is the first study to show that mammalian cochlear hair cells also retain the capacity to self-repair the tip links. It has been suggested that regeneration of tip links may underlie recovery from temporary threshold shift (Zhao et al., 1996). In culture conditions, chick hair cells can repair their broken tip links soon after the tip links are broken and majority of the tip links are regenerated within $24 \mathrm{~h}$ (Zhao et al., 1996). These authors show that new protein synthesis is not required for regeneration and that intracellular calcium can influence tip-link regeneration. The mechanisms of tip-link regeneration are not clear. However, two possible mechanisms are proposed by Zhao et al. (1996): (1) Tip links could be formed by $\mathrm{Ca}^{2+}$-dependent interaction of two extended subunits, each a transmembrane protein; (2) A tip link could be formed when an extracellular protein binds in a $\mathrm{Ca}^{2+}$-dependent manner to transmembrane receptors.

It appears that, in mammals, whether hearing can recover after temporary or permanent threshold shift is ultimately determined by the ability to regenerate tip links, and the inability to regenerate the stereociliary bundles and hair cells. Since mammalian cochlear hair cells can survive for $\sim 2$ weeks after loss of their stereociliary bundles, this window of opportunity is crucial for maintaining injured hair cells and subsequently repairing the hair bundle using genetic or chemical therapeutic interventions to prevent permanent hair cell loss.

\section{References}

Ashmore JF (1989) Transducer motor coupling in cochlear outer hair cells. New York: Plenum.

Assad JA, Shepherd GMG, Corey DP (1991) Tip-link integrity and mechanical transduction in vertebrate hair cells. Neuron 7:985-994.

Baird RA, Steyger PS, Schuff NR (1996) Mitotic and nonmitotic hair cell regeneration in the bullfrog vestibular otolith organs. Ann N Y Acad Sci 781:59-70.

Baird RA, Burton MD, Lysakowski A, Fashena DS, Naeger RA (2000) Hair cell recovery in mitotically blocked cultures of the bullfrog saccule. Proc Natl Acad Sci U S A 97:11722-11729.

Baker K, Brough DE, Staecker H (2009) Repair of the vestibular system via adenovector delivery of Atoh1: a potential treatment for balance disorders. Adv Otorhinolaryngol 66:52-63.

Bartles JR (2000) Parallel actin bundles and their multiple actin-bundling proteins. Curr Opin Cell Biol 12:72-78.

Belyantseva IA, Adler HJ, Curi R, Frolenkov GI, Kachar B (2000) Expression and localization of prestin and the sugar transporter GLUT-5 during development of electromotility in cochlear outer hair cells. J Neurosci 20:RC116(1-5)

Belyantseva IA, Boger ET, Friedman TB (2003) Myosin XVa localizes to the tips of inner ear sensory cell stereocilia and is essential for staircase formation of the hair bundle. Proc Natl Acad Sci U S A 100:13958-13963.

Crawford AC, Evans MG, Fettiplace R (1991) The actions of calcium on the mechano-electrical transducer current of turtle hair cells. J Physiol 434:369-398.

Fettiplace R, Hackney CM (2006) The sensory and motor roles of auditory hair cells. Nat Rev Neurosci 7:19-29.

Forge A, Li L, Corwin JT, Nevill G (1993) Ultrastructural evidence for hair cell regeneration in the mammalian inner ear. Science 259:1616-1619.

Furness DN, Richardson GP, Russell IJ (1989) Stereociliary bundle morphology in organotypic cultures of the mouse cochlea. Hear Res 38:95-109.

Gale JE, Meyers JR, Periasamy A, Corwin JT (2002) Survival of bundleless hair cells and subsequent bundle replacement in the bullfrog's saccule. J Neurobiol 50:81-92.

Géléoc GS, Holt JR (2003) Developmental acquisition of sensory transduction in hair cells of the mouse inner ear. Nat Neurosci 6:1019-1020.

Gillespie PG, Corey DP (1997) Myosin and adaptation by hair cells. Neuron 19:955-958.

Goodyear RJ, Marcotti W, Kros CJ, Richardson GP (2005) Development and properties of stereociliary link types in hair cells of the mouse cochlea. J Comp Neurol 485:75-85.

Gorelik J, Shevchuk AI, Frolenkov GI, Diakonov IA, Lab MJ, Kros CJ, Richardson GP, Vodyanoy I, Edwards CR, Klenerman D, Korchev YE (2003) Dynamic assembly of surface structures in living cells. Proc Natl Acad Sci U S A 100:5819-5822.

He DZZ (1997) Relationship between the development of outer hair cell electromotility and efferent innervation: a study in cultured organ of Corti of neonatal gerbils. J Neurosci 17:3634-3643.

He DZZ, Dallos P (1999) Somatic stiffness of cochlear outer hair cells is voltage-dependent. Proc Natl Acad Sci U S A 96:8223-8228.

He DZZ, Evans BN, Dallos P (1994) First appearance and development of electromotility in neonatal gerbil outer hair cells. Hear Res 78:77-90.

He DZZ, Zheng J, Dallos P (2001) Development of acetylcholine receptors in cultured outer hair cells. Hear Res 162:113-125.

He DZZ, Jia S, Dallos P (2004) Mechanoelectrical transduction of adult outer hair cells studied in a gerbil hemicochlea. Nature 429:766-770.

Holley MC (2002) Application of new biological approaches to stimulate sensory repair and protection. Br Med Bull 63:157-169.

Holt JR, Corey DP, Eatock RA (1997) Mechanoelectrical transduction and adaptation in hair cells of the mouse utricle, a low-frequency vestibular organ. J Neurosci 17:8739-8748.

Holt JR, Gillespie SK, Provance DW, Shah K, Shokat KM, Corey DP, Mercer JA, Gillespie PG (2002) A chemical-genetic strategy implicates myosin-1c in adaptation by hair cells. Cell 108:371-381.

Hudspeth AJ, Corey DP (1977) Sensitivity, polarity and conductance change in the response of vertebrate hair cells to controlled mechanical stimuli. Proc Natl Acad Sci U S A 74:2407-2411.

Jia S, Dallos P, He DZ (2007) Mechanoelectric transduction of adult inner hair cells. J Neurosci 27:1006-1014.

Jia S, He DZZ (2005) Motility-associated hair bundle motion of outer hair cells. Nat Neurosci 8:1028-1034.

Kazmierczak P, Sakaguchi H, Tokita J, Wilson-Kubalek EM, Milligan RA, Müller U, Kachar B (2007) Cadherin 23 and protocadherin 15 interact to form tip-link filaments in sensory hair cells. Nature 449:87-91.

Kennedy HJ, Evans MG, Crawford AC, Fettiplace R (2003) Fast adaptation of mechanoelectrical transducer channels in mammalian cochlear hair cells. Nat Neurosci 6:832-836.

Kros CJ, Rüsch A, Richardson GP (1992) Mechano-electrical transducer currents in hair cells of the cultured neonatal mouse cochlea. Proc Biol Sci 249:185-193.

Kros CJ, Ruppersberg JP, Rüsch A (1998) Expression of a potassium current in inner hair cells during development of hearing in mice. Nature 394:281-284.

Liberman MC, Gao J, He DZZ, Wu X, Jia S, Zuo J (2002) Prestin is required for outer hair cell motility and the cochlear amplifier. Nature 419:300-304.

Marcotti W, Johnson SL, Holley MC, Kros CJ (2003) Developmental changes in the expression of potassium currents of embryonic, neonatal and mature mouse inner hair cells. J Physiol 548:383-400.

Nayak GD, Ratnayaka HS, Goodyear RJ, Richardson GP (2007) Develop- 
ment of the hair bundle and mechanotransduction. Int J Dev Biol 51:597-608.

Oliver D, Fakler B (1999) Expression density and functional characteristics of the outer hair cell motor protein are regulated during postnatal development in rat. J Physiol 519:791-800.

Pickles JO, Comis SD, Osborne MP (1984) Cross-links between stereocilia in the guinea-pig organ of Corti and their possible relation to sensory transduction. Hear Res 15:103-112.

Pickles JO, Osborne MP, Comis SD (1987) Vulnerability of tip links between stereocilia to acoustic trauma in the guinea pig. Hear Res 25:173-183.

Ricci AJ, Crawford AC, Fettiplace R (2002) Mechanisms of active hair bundle motion in auditory hair cells. J Neurosci 22:44-52.

Ricci AJ, Crawford AC, Fettiplace R (2003) Tonotopic variation in the conductance of the hair cell mechanotransducer channel. Neuron 40:983-990.

Ricci AJ, Kennedy HJ, Crawford AC, Fettiplace R (2005) The transduction channel filter in auditory hair cells. J Neurosci 25:7831-7839.

Rüsch A, Lysakowski A, Eatock RA (1998) Postnatal development of type I and type II hair cells in the mouse utricle: acquisition of voltage-gated conductances and differentiated morphology. J Neurosci 18:7487-7501.

Russell IJ, Richardson GP (1987) The morphology and physiology of hair cells in organotypic cultures of the mouse cochlea. Hear Res 31:9-24.

Rzadzinska AK, Schneider ME, Davies C, Riordan GP, Kachar B (2004) An actin molecular treadmill and myosins maintain stereocilia functional architecture and self-renewal. J Cell Biol 164:887-897.

Santos-Sacchi J (1989) Asymmetry in voltage-dependent movements of isolated outer hair cells from the organ of Corti. J Neurosci 9:2954-2962.

Santos-Sacchi J, Wu M, Kakehata S (2001) Furosemide alters nonlinear capacitance in isolated outer hair cells. Hear Res 159:69-73.
Schneider ME, Belyantseva IA, Azevedo RB, Kachar B (2002) Rapid renewal of auditory hair bundles. Nature 418:837-838.

Sobkowicz HM, August BK, Slapnick SM (1992) Epithelial repair following mechanical injury of the developing organ of Corti in culture: an electron microscopic and autoradiographic study. Exp Neurol 115:44-49.

Sobkowicz HM, Loftus JM, Slapnick SM (1993) Tissue culture of the organ of Corti. Acta Otolaryngol Suppl 502:3-36.

Sobkowicz HM, August BK, Slapnick SM (1996) Post-traumatic survival and recovery of the auditory sensory cells in culture. Acta Otolaryngol 116:257-262.

Tilney LG, Tilney MS (1986) Functional organization of the cytoskeleton. Hear Res 22:55-77.

Tilney LG, Cotanche DA, Tilney MS (1992) Actin filaments, stereocilia and hair cells of the bird cochlea. VI. How the number and arrangement of stereocilia are determined. Development 116:213-226.

Waguespack J, Salles FT, Kachar B, Ricci AJ (2007) Stepwise morphological and functional maturation of mechanotransduction in rat outer hair cells. J Neurosci 27:13890-13902.

Warchol ME, Lambert PR, Goldstein BJ, Forge A, Corwin JT (1993) Regenerative proliferation in inner ear sensory epithelia from adult guinea pigs and humans. Science 259:1619-1622.

Zhao Y, Yamoah EN, Gillespie PG (1996) Regeneration of broken tip links and restoration of mechanical transduction in hair cells. Proc Natl Acad Sci U S A 93:15469-15474.

Zheng J, Shen W, He DZZ, Long KB, Madison LD, Dallos P (2000) Prestin is the motor protein of cochlear outer hair cells. Nature 405:149-155.

Zheng JL, Keller G, Gao WQ (1999) Immunocytochemical and morphological evidence for intracellular self-repair as an important contributor to mammalian hair cell recovery. J Neurosci 19:2161-2170. 